\title{
Response and evoked potential latencies associated with commission errors in visual monitoring
}

\author{
R. PARASURAMAN and D. R. DAVIES \\ University of Aston, Gosta Green, Birmingham B4 7ET, England
}

\begin{abstract}
Eight male subjects performed a 40-min visual monitoring task in which they were required to detect the occasional dim flash from a background of brighter flashes. Response latencies associated with correct detections (CDs) and commission errors (CEs) were recorded, as were the peak latencies of evoked potential (EP) components averaged separately for each of the two response categories. Response latencies for CEs were significantly longer than those for CDs, and "late" EP component latencies $\left(\mathrm{P}_{2}, \mathrm{~N}_{2}\right.$, and $\mathrm{P}_{3}$ ) associated with $\mathrm{CEs}$ were also significantly longer than component latencies associated with CDs. These results are discussed with reference to EP concomitants of decision processes and to various theories of monitoring behavior.
\end{abstract}

Commission errors, or false positives, frequently occur in the performance of monitoring tasks and have been systematically treated within the framework of signal detection theory, as a manifestation of the subject's degree of caution in reporting an event as a signal (Broadbent, 1971). However, one aspect of commission errors that has received little attention is the latency associated with such errors. When response latencies have been discussed in relation to vigilance performance, only lattencies associated with correct detections have been considered (cf. Buck, 1966). A few studies have investigated latencies associated with commission errors and other responses in detection and discrimination tasks of brief duration (Nickerson, 1973; Pike, 1971; Sekuler, 1965), but no similar studies have been reported for prolonged monitoring or vigilance tasks.

In a review of the various response measures used in describing performance at vigilance tasks, Davies and Tune (1970) briefly reported the findings of two unpublished studies in which latency data for different types of response were collected. In particular, they pointed out that in both studies, latencies associated with commission errors (CEs) were considerably longer than latencies associated with correct detections (CDs) and that both latencies increased with time on task. These preliminary lindings are further investigated in the experiment reported here. In a 40-min visual monitoring task, response latencies for CEs and CDs were recorded. Furthermore, in order to obtain physiological correlates of possible latency differences between CEs and CDs, averaged visual evoked potentials (EPs) were also recorded. EPs were averaged separately for CEs and CDs. There is some evidence that latency

The authors' complete address: Department of Applied Psychology, Coliege House. University of Aston in Birmingham. Gosta Green, Birmingham B4 7ET, England. measures of EP components are sensitive to betweenand within-subject differences in response latency (Donchin \& Lindsley, 1966; Ritter, Simson, \& Vaughan, 1972).

\section{METHOD}

\section{Monitoring Task}

The monitoring task consisted of a series of circular light tlashes occurring regularly every $4 \mathrm{sec}$ (nonsignals) which were occasionally and randomly replaced by dimmer flashes (signals), with the restriction that the temporal location of signals in the two halves of the 40-min task was the same. The decrease in brightness that defined a signal was $0.05 \log \mathrm{fL}$. Subjects responded to every event by depressing one of two microswitches, "Yes" for signals and "No" for nonsignals. Intersignal intervals were randomized within successive $5-\mathrm{min}$ blocks, and 120 signals were presented during the 40-min vigil, 60 in each half of the task. The light flashes $(33 \mathrm{msec}$ in duration) were presented to the right eye in Maxwellian view at a visual angle of $2 \mathrm{deg}$. The subjects fixated a faint spot appearing at the center of flashes.

\section{Recording of Evoked Potentials}

The EEG was recorded from scalp $\mathrm{Ag}-\mathrm{AgCl}$ electrodes at the right occiput $(02)$ referred to the right earlobe $\left(A_{2}\right)$ with a ground electrode at the left earlobe $\left(A_{1}\right)$. Scalp signals were amplified by a high-gain preamplitier, bandpass $1-50 \mathrm{~Hz}$, and then fed to the A-D in put of a PDP-9 computer for sampling and averaging. EPs were averaged separately from CEs and CDs for each half of the task. ${ }^{1}$ Response times and EP data were also collected for the other two response categories (omissions and correct rejections) but are not reported here.

\section{Subjects}

The subjects were eight young adult males aged 18 to 24 , all of whom had normal EEGs and no visual abnormalities. Before performing at the monitoring task, each subject was trained and then given a 10 -min practice task in which the same signal and event rates as in the main task were used.

\section{RESULTS}

\section{Response Latencies}

Table 1 gives the means and the standard deviations of the response latencies associated with CDs and CEs for both halves of the 
Table 1

Mean Response Latencies (Milliseconds) for Correct Detections and Commission Errors for the Two Halves of the 40-Min Monitoring Task

\begin{tabular}{|c|c|c|c|c|}
\hline & \multicolumn{2}{|c|}{ Correct Detections } & \multicolumn{2}{|c|}{ Commission Errors } \\
\hline & $\begin{array}{l}\text { First } \\
\text { Half }\end{array}$ & $\begin{array}{c}\text { Second } \\
\text { Half }\end{array}$ & $\begin{array}{l}\text { First } \\
\text { Half }\end{array}$ & $\begin{array}{c}\text { Second } \\
\text { Half }\end{array}$ \\
\hline Mean & 693 & 751 & 895 & 973 \\
\hline SD & 46 & 53 & 67 & 59 \\
\hline $\mathbf{N}$ & 40 & 32 & 28 & 20 \\
\hline
\end{tabular}

Note $-N$ represents the mean number of observations per subject from which the mean response latency was determined.

task. Latency differences between response categories and within the same response category in both halves of the task were analyzed using a Wilcoxon matched pairs signed-ranks test (Siegel, 1956).

The results were that for both halves of the task, the mean response latency associated with CEs was significantly greater than that associated with CDs $(\mathrm{p}<.005$ in both cases). This difference was found in all eight subjects, the lowest number of commission errors made by any subject being 16 . In addition, both $C E$ and $C D$ latencies increased signiticantly from the tirst half of the task to the second $(p<.01$ in both cases). and this increase in $C E$ latencies was significantly greater than the increase in $C D$ latencies $(p<.01)$. Finally, for each half of the task, Spearman rank correlation coefficients were computed between the number of correct detections and the number of commission errors and between the mean latencies associated with the two response categories. In the first case, the correlation coefficients were, for the first half of the task, 0.58 and, for the second, 0.54 . In the latter case, they were 0.51 and 0.43 , respectively. None of these values reaches an acceptable level of significance.

\section{EP Component Latencies}

Figure 1 shows, for two subjects, the EPs averaged to CDs and CEs in both halves of the task, while Table 2 gives the means and, in brackets, the standard deviations of the components, $\mathrm{P}_{1}, \mathrm{~N}_{1}, \mathrm{P}_{2}, \mathrm{~N}_{2}$, and $P_{3}$. Individual EP peaks were identified as the most positive or most negative turning points in each EP wave form. within 10-msec windows. Differences in latency between EP components were tested for both halves of the task, using the Wilcoxon matched pairs signed-ranks test.

For both halves of the task. EPs averaged to CEs had significantly longer latencies than EPs averaged to $C D s$ only when the three later components, $P_{2}, N_{2}$, and $\mathrm{P}_{3}$, were considered $(\mathrm{p}<.005$ in each case). No such significant differences were found for components $P_{1}$ and $N_{1}$. As with the response latency measures. these EP component latency differences were found in all subjects. EP component latencies were also tested for differences between the two halves of the task, using Wilcoxon's signed-ranks test. Only the latencies of $\mathrm{P}_{2}, \mathrm{~N}_{2}$, and $\mathrm{P}_{3}$ increased significantly from the tirst half of the task to the second $(p<.01$ in all cases). The latencies of the $P_{1}$ and $N_{1}$ components showed no such increase.

\section{Correlations Between Response Measures and EP Component Latencies}

Spearman rank correlation coefficients were also computed between latencies associated with CDs and CEs and EP component latencies for the three later components $P_{2}, N_{2}$, and $P_{3}$. These are shown in Table 3. As can be seen from this table, uniformly high and signiticant correlations are obtained between response latency and the corresponding EP component latency, but not otherwise, except in the case of $\mathrm{N}_{2}$ in the second half of the task, where the correlation between the EP component latencies for CDs and CEs just reaches significance at the .05 level. This anomaly apart. it appears that the EP component latency data faithfully reflect differences in response latency between subjects.

\section{DISCUSSION}

The results of this experiment indicate that throughout the 40-min task. correct identifications of

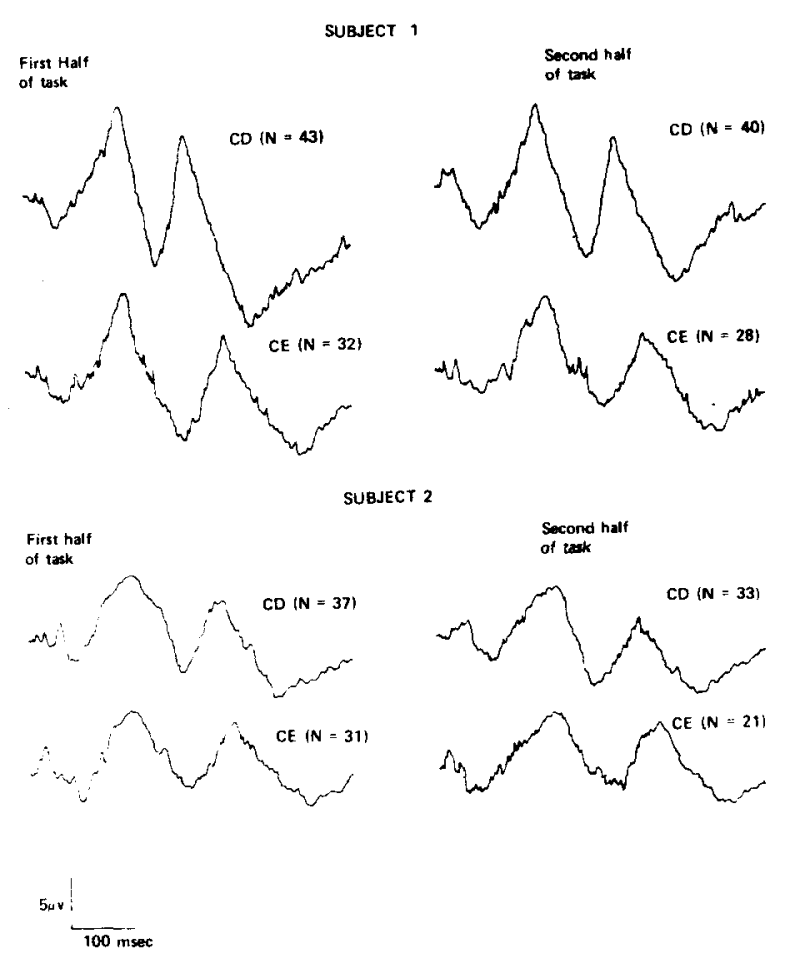

Figure 1. Averaged evoked potential data associated with correct detections (CD) and commission errors (CE) for two subjects for the two halves of the test. Numbers of observations are shown in brackets. 
events as signals were made signiticantly faster than incorrect identifications of nonsignal events as signals. This increase in processing time associated with false positive responses was accompanied by similar increases in the latencies of the late components $\left(P_{2}, N_{2}\right.$, and $\left.P_{1}\right)$ of the EP averaged to CEs.

A number of studies have investigated the late components of the EP in relation to information processing or decision making (Hillyard, Hink, Schwent. \& Picton, 1974; Karlin, 1970; Roth \& Kopell. 1973). The general finding has been that the $\mathbf{P}_{3}$ wave is generated or enhanced when task-relevant information is delivered. On the basis of these and other studies, Picton and Hillyard (1974) have recently proposed that the evoked response to a detected signal comprises two distinct parts: a sensory evoked response and a later perceptual decision complex which is manifested in the amplitude enhancement of the late EP components. Most of the above-mentioned studies have used amplitude mealsures in studying late component changes; one study, however, has reported latency differences in $\mathbf{P}_{3}$ related to the difficulty of an auditory discrimination (Ritter et al., 1972). Posner, Klein, Summers, and Buggie (1973) have also brietly reported that differences in latency between pairs of stimuli judged as "same" or "different" are accompanied by reliable differences in late-component $(160-350 \mathrm{msec})$ latencies between EPs averaged to the "same" and "different" responses. ${ }^{2}$ This briefly reported result is of the same form as the results of the present experiment, in which latency differences in late components $(180-450 \mathrm{msec})$ were associated with response latency differences between CEs and CDs. Both sets of results appear to support the suggestion of Ritter et al. (1972) that the latency of late EP components represent temporal correlates of the information processing and decision-making activity preceding a behavioral response.

Table 2

Mean EP Component Latencies (Milliseconds) for Correct Detections and Commission Errors for the Two Halves of the 40-Min Monitoring Task

\begin{tabular}{|c|c|c|c|c|}
\hline \multirow[b]{2}{*}{$\begin{array}{c}\text { EP } \\
\text { Compo- } \\
\text { nents }\end{array}$} & \multicolumn{2}{|c|}{ Correct Detections } & \multicolumn{2}{|c|}{ Commission Errots } \\
\hline & $\begin{array}{c}\text { First } \\
\text { Half } \\
(\mathrm{N}=40)\end{array}$ & $\begin{array}{c}\text { Second } \\
\text { Half } \\
(\mathrm{N}=32)\end{array}$ & $\begin{array}{c}\text { First } \\
\text { Half } \\
(\mathrm{N}=28)\end{array}$ & $\begin{array}{c}\text { Second } \\
\text { Half } \\
(N=20)\end{array}$ \\
\hline $\begin{array}{l}P_{1} \\
N_{1} \\
P_{2} \\
N_{2} \\
P_{3}\end{array}$ & $\begin{aligned} 75 & (19) \\
160 & (23) \\
218 & (32) \\
271 & (39) \\
341 & (57)\end{aligned}$ & $\begin{aligned} 78 & (24) \\
174 & (34) \\
251 & (35) \\
285 & (34) \\
360 & (60)\end{aligned}$ & $\begin{array}{rr}70 & (20) \\
165 & (32) \\
249 & (34) \\
301 & (29) \\
412 & (66)\end{array}$ & $\begin{aligned} & 73(18) \\
& 176(29) \\
& 261(37) \\
& 332(30) \\
& 424(74) \\
&\end{aligned}$ \\
\hline
\end{tabular}

Note-N represents the mean number of observations per subject from which the mean EP component latency was determined. Standard deviations are shown in brackets.
Table 3

Spearman Rank Correlation Coefficients Between Mean Response Latencies for $\operatorname{CDs}\left(C_{L}\right)$ and $C E s\left(C E_{L}\right)$ and the Mean EP Component Latencies for $P_{2}, N_{2}$, and $P_{3}$ Associated With CDs $\left[\mathrm{P}_{2}(\mathrm{CD}), \mathrm{N}_{2}(\mathrm{CD}), \mathrm{P}_{3}\right.$ (CD)] and CEs $\left[\mathrm{P}_{2}(\mathrm{CE})\right.$, $N_{2}$ (CE), $P_{3}$ (CE)] for the Two Halves of the 40-Min Visual Monitoring Task

\begin{tabular}{|c|c|c|c|c|c|}
\hline \multicolumn{2}{|c|}{ EP Component } & \multicolumn{2}{|c|}{ First Half } & \multicolumn{2}{|c|}{ Second Half } \\
\hline$P_{2}$ & $\begin{array}{l}\mathrm{CD}_{\mathrm{L}} \\
\mathrm{CE}_{\mathrm{L}} \\
\mathrm{P}_{2}(\mathrm{CD})\end{array}$ & $\begin{array}{c}P_{2}(C D) \\
.68^{*} \\
.21\end{array}$ & $\begin{array}{c}\mathrm{P}_{2}(\mathrm{CE}) \\
.41 \\
.74 * \\
.22\end{array}$ & $\begin{array}{c}P_{2}(C D) \\
.66^{*} \\
.16\end{array}$ & $\begin{array}{c}P_{2}(C E) \\
.47 \\
.79 * \\
.18\end{array}$ \\
\hline $\mathrm{N}_{2}$ & $\begin{array}{l}C D_{L} \\
C E_{L} \\
N_{2}(C D)\end{array}$ & $\begin{array}{c}\mathrm{N}_{2}(\mathrm{CD}) \\
.73^{*} \\
.30\end{array}$ & $\begin{array}{c}\mathrm{N}_{2}(\mathrm{CE}) \\
.31 \\
.74^{*} \\
.29\end{array}$ & $\begin{array}{c}\mathrm{N}_{2}(\mathrm{CD}) \\
.81^{*} \\
.40\end{array}$ & $\begin{array}{c}\mathrm{N}_{2}(\mathrm{CE}) \\
.26 \\
.79^{*} \\
.65^{*}\end{array}$ \\
\hline$P_{3}$ & $\begin{array}{l}\mathrm{CD}_{\mathrm{L}} \\
\mathrm{CE}_{\mathrm{L}} \\
\mathrm{P}_{3}(\mathrm{CD})\end{array}$ & $\begin{array}{c}\mathrm{P}_{3}(\mathrm{CD}) \\
.85 * * \\
.39\end{array}$ & $\begin{array}{c}P_{3}(C E) \\
.25 \\
.90^{* *} \\
.53\end{array}$ & $\begin{array}{c}P_{3}(C D) \\
.87^{* *} \\
.47\end{array}$ & $\begin{array}{c}P_{3}(\mathrm{CE}) \\
.28 \\
.93^{* *} \\
.41\end{array}$ \\
\hline
\end{tabular}

$* p<.05 \quad * *<.01$

The finding that latencies associated with CDs significantly increase with time on task is well established (Buck, 1966). The present study also demonstrates a significant increase with time on task in latencies associated with CEs. In addition, the latencies of the late components of EPs averaged to both CEs and CDs significantly increase with time at work. It thus appears that latencies of late EP components are sensitive not only to mean latency differences between response categories but also to latency increases with time on task within each response category. The most parsimonious explanation of these findings is, perhaps, that the subjects became progressively less certain of the responses they made as a function of time at work. This may be due to a combination of several factors, among which are expectancy changes and reductions in arousal (Davies $\&$ Tune, 1970).

\section{REFERENCES}

Broadbent, D. E. Decision and stress. London: Academic Press, 1971 .

Buck, L. Reaction time as a measure of perceptual vigilance. Psychological Bulletin, 1966, 65, 291-308.

Davies, D. R., \& Tune, G. S. Human vigilance performance. London: Staples Press, 1970.

Donchin, E.. \& Lindsley, D. B. Average evoked potentials and reaction time to visual stimuli. Electroencephalography and Clinical Neu rophysiology, 1966, 20, 217-223.

Hillyard, S. A., Hink, R. F., Schwent, V. L., \& Picton, T. W. Electrical signs of selective attention in the human brain. Science, 1974, 182, 177-179.

KarLIN, L. Cognition, preparation and sensory evoked potentials. Psychological Bulletin. 1970, 73, 122-136. 
Nickerson. R. S. The use of binary-classitication tasks in the study of human intormation processing: A tutorial survey. In S. Kornblum (Ed.). Attention and performance $I V$. London: Academic Press. 1973.

Picton, T. W., \& Hillyakd, S. A. Human alditory evoied potentials. II: Effects of allention. Electrosencepialography and Climical Neurophysiology, 1974, 36. 191-199.

Pine, A. R. The latencies of correct and incorrect responses in discrimination and detection tasks: Their interpretation in terms ot a model based on simple counting. Perceprion \& Psychophysics, $1971,9.455-460$.

Posner. M. J.. Klein, R., Simson, J., \& Buggie, J. On the selection of signals. Memory and Cognition. 1973, 1. 2-12.

Ritter. W.. Simson, R.. \& Vaughan. H. G., JR. Association cortex potentials and reaction time in auditory discrimination. Electroencephalography and Clinical Newrophysiology. 1972, 36. 219-225.

Roth. W. T., \& Kopell, B. S. P300: An orienting response in the human AER. Perceptual and Motor Skills. 1973. 36. 219.225 .

Sekuler. R. W. Signal detection, choice response times, and visual backward masking. Canadian Journal of Psychology. 1965, 19. $118-132$.

SIEgel. S. Nonparametric statistics for the behavioural sciences. London: McGraw-Hill, 1956.

\section{NOTES}

1. The EEC was continuously monitored throughout the session on an SLE Galileo recorder. Artifact contamination of the EPs was minimized by excluding EEG epochs containing muscle or eve-blink artifacts from the averaging process. Control runs. in which subjects were instructed merely to count critical signals or to delay response by 1 see, indicated that overt responding did not contaminate the EP.

2. It should be noted that in the present experiment response latencies for both CDs and CEs were considerably longer than the peak latency of $P_{3}$, by, on average, $3(0)-4(0)$ misec. This finding contrasts with those of Ritter et al. (1972) and Posner et al. (1973) and adds further support for the view that $P_{3}$ is a concomitant of decision-making activity rather than of motor activity associated with owert responding.
(Received for publication July 17. 1974; revision received Nowember 0,1974 .) 